\title{
The synergistic effect of propofol and ulinastatin suppressed the viability of the human lung adenocarcinoma epithelial A549 cell line
}

\author{
PING LI ${ }^{1 *}$, PEIPEI GUO ${ }^{1 *}$, CHUNSHUI LIN ${ }^{1}$, MURONG HE ${ }^{1}$, XIAOQING ZHU ${ }^{1}$, \\ CHUAN LIU $^{1}$, JING TANG ${ }^{1}$, WEI WANG ${ }^{1}$ and WEIDONG LIANG ${ }^{2}$ \\ ${ }^{1}$ Department of Anesthesia, Nanfang Hospital, Southern Medical University, Guangzhou, Guangdong 510515; \\ ${ }^{2}$ Department of Anesthesia, First Affiliated Hospital, Gannan Medical College, Ganzhou, Jiangxi 341000, P.R. China
}

Received September 11, 2017; Accepted July 20, 2018

DOI: $10.3892 / \mathrm{ol} .2018 .9283$

\begin{abstract}
Ulinastatin and propofol (PPF) are recognized for their anticancer properties. The aim of the present study was to evaluate the synergistic antitumor effect of PPF followed by ulinastatin against A549 cells. In MTT assays, PPF (10, 20 and $30 \mu \mathrm{M}$ ) followed by $200 \mathrm{U} / \mathrm{ml}$ ulinastatin was more effective at inhibiting A549 cell viability compared with PPF (10, 20 and $30 \mu \mathrm{M})$ or $200 \mathrm{U} / \mathrm{ml}$ ulinastatin. PPF $(10,20$ and $30 \mu \mathrm{M})$ followed by $200 \mathrm{U} / \mathrm{ml}$ ulinastatin treatments synergistically increased the number of $\mathrm{S}$ cells and synergistically reduced the number of G2/M cells associated with PPF stimulation in a dose-dependent manner. Western blot analysis demonstrated that the antitumor effect of PPF followed by $200 \mathrm{U} / \mathrm{ml}$ ulinastatin treatments were associated with the downregulated expression of extracellular signal-regulated kinase 1 and 2 phosphorylation (p-ERK1/2) and matrix metalloproteinases 2 (MMP-2). In conclusion, these data demonstrated that PPF (20 and $30 \mu \mathrm{M}$ ) followed by $200 \mathrm{U} / \mathrm{ml}$ ulinastatin treatments synergistically stimulated a significant proportion of A549 cells in $\mathrm{S}$ phase. Furthermore, the combination synergistically reduced a significant proportion of A549 cells in G2/M phase and synergistically suppressed the viability of A549 cells, which was possibly related regulation of the expression of p-ERK1/2 and MMP-2 in A549 cells.
\end{abstract}

Correspondence to: Professor Chunshui Lin, Department of Anesthesia, Nanfang Hospital, Southern Medical University, 1838 Guangzhou North Road, Guangzhou, Guangdong 510515, P.R. China

E-mail: linchunshui2014@163.com

*Contributed equally

Key words: A549 cells, ulinastatin, propofol, matrix metalloproteinases 2, extracellular signal-regulated kinase 1 and 2 phosphorylation, antitumor

\section{Introduction}

Among all types of lung cancers, adenocarcinoma accounts for $\sim 40 \%$ and generally has both a poor prognosis and increased potential for metastases (1). Currently, surgery is the primary treatment for cancer. However, surgery itself can stimulate cell growth (2), metastasis (3) and recurrence (4) of cancer. Anesthetic agents administered during surgery might influence the cell activities of cancer simultaneously (5).

Propofol (PPF) is a sedative-hypnotic agent, which is widely used in operating rooms and intensive care units (ICU) for smooth induction and rapid recovery from anesthesia. Potential anticancer properties of PPF have been considered. PPF inhibits the invasion and migration of the human lung adenocarcinoma epithelial A549 cell line by regulating matrix metalloproteinases-2 (MMP-2) and p38 MAPK signaling pathways (6). Furthermore, it induces apoptosis in A549 cells through extracellular signal-regulated kinase 1 and 2 (ERK1/2) pathways (7). As a urinary trypsin inhibitor, ulinastatin also has properties that suppress cancer cell growth, proliferation, differentiation and migration (8-13). Studies have shown that the anticancer drugs combined with ulinastatin could offer therapeutic promise for cancer treatment (14-16).

At present, the effects of PPF in combination with ulinastatin on post-perfusion lung syndrome (17) and acute lung injury (18) have been demonstrated. However, antitumor effects associated with different ulinastatin and PPF administration against A549 cells remain unclear and the delivery of PPF (10, 20 and $30 \mu \mathrm{M}$ ) followed by $200 \mathrm{U} / \mathrm{ml}$ ulinastatin treatments on cancer cells has not been studied. The aim of this study is to evaluate the synergistic antitumor effect of PPF followed by ulinastatin against A549 cells. The expression of p-ERK1/2 and MMP-2 was detected to identify the mechanisms behind the antitumor effects of PPF $(10,20$ and $30 \mu \mathrm{M})$ followed by $200 \mathrm{U} / \mathrm{ml}$ ulinastatin.

\section{Materials and methods}

Cell culture. The A549 cell line was obtained from the Cancer Research Institute of the Southern Medical University (Guangdong, China). Cells were maintained at $37^{\circ} \mathrm{C}$ in a 
humidified atmosphere of $95 \%$ air and $5 \% \mathrm{CO}_{2}$ in DMEM/F-12 with $10 \%$ fetal bovine serum (FBS; both Gibco; Thermo Fisher Scientific, Inc., Waltham, MA, USA), 100 units/ml penicillin and $100 \mathrm{ng} / \mathrm{ml}$ streptomycin (Sigma-Aldrich; Merck KGaA, Darmstadt, Germany).

Different treatment schedules for A549 cells. To evaluate the antitumor effect of different treatment schedules with PPF (Sigma-Aldrich; Merck KGaA) and ulinastatin (Techpool Bio-Pharma, Guangzhou, China), cells were treated with seven different treatments (Fig. 1A). According to the studies of Kobayashi (8) and Song (7), the concentrations of $800 \mathrm{U} / \mathrm{ml}$ ulinastatin and $100 \mu \mathrm{M}$ PPF were selected as the optimum doses. The control was defined as continuous treatment with serum-free medium for $48 \mathrm{~h}$; $0.1 \%$ DMSO was defined as continuous treatment with $0.1 \%$ DMSO for $48 \mathrm{~h} ; 800 \mathrm{U} / \mathrm{ml}$ ulinastatin was defined as continuous $800 \mathrm{U} / \mathrm{ml}$ ulinastatin treatment for $48 \mathrm{~h} ; 100 \mu \mathrm{M}$ PPF was defined as pretreatment with serum-free medium for $42 \mathrm{~h}$, followed by aspiration, one wash with phosphate buffer saline (PBS), and PPF $(100 \mu \mathrm{M})$ treatment for $6 \mathrm{~h} ; 800 \mathrm{U} / \mathrm{ml}$ ulinastatin $+100 \mu \mathrm{M}$ PPF was defined as pretreatment with $800 \mathrm{U} / \mathrm{ml}$ ulinastatin for $42 \mathrm{~h}$, followed by aspiration, one wash with PBS, and concomitant treatment with both $800 \mathrm{U} / \mathrm{ml}$ ulinastatin and $100 \mu \mathrm{M}$ PPF for $6 \mathrm{~h} ; 800 \mathrm{U} / \mathrm{ml}$ ulinastatin $\rightarrow 100 \mu \mathrm{M}$ PPF was defined as pretreatment with $800 \mathrm{U} / \mathrm{ml}$ ulinastatin for $42 \mathrm{~h}$, followed by aspiration, one wash with PBS, and $100 \mu \mathrm{M}$ PPF treatment for $6 \mathrm{~h} ; 100 \mu \mathrm{M} \mathrm{PPF} \rightarrow 800 \mathrm{U} / \mathrm{ml}$ ulinastatin was defined as pretreatment with $100 \mu \mathrm{M}$ PPF for $6 \mathrm{~h}$, followed by aspiration, one wash with PBS, and $800 \mathrm{U} / \mathrm{ml}$ ulinastatin treatment for $42 \mathrm{~h}$. The maximum concentration of DMSO (Sigma-Aldrich; Merck $\mathrm{KGaA}$ ) added to the medium in this study was $0.1 \%$.

From the results of the first experimental block, we found that the antitumor of the sequence PPF $\rightarrow$ ulinastatin at high concentrations was the optimum sequence. To verify the synergistic antitumor effect of PPF $\rightarrow$ ulinastatin at a low concentration, a concentration gradient of PPF was generated: This increased from $10,20,30 \mu \mathrm{M}$, while the concentration of ulinastatin was $200 \mathrm{U} / \mathrm{ml}$ (Fig. 1B). Control was defined as continuous treatment with serum-free medium for $48 \mathrm{~h}$; $0.1 \%$ DMSO was defined as continuous treatment with $0.1 \%$ DMSO for $48 \mathrm{~h} ; 200 \mathrm{U} / \mathrm{ml}$ ulinastatin was defined as pretreatment with serum-free medium for $6 \mathrm{~h}$, followed by aspiration, one wash with PBS, and $200 \mathrm{U} / \mathrm{ml}$ ulinastatin treatment for $42 \mathrm{~h}$; the PPF group was defined as pretreatment with PPF $(10,20,30 \mu \mathrm{M})$ for $6 \mathrm{~h}$, followed by aspiration, one wash with $\mathrm{PBS}$, and incubation in serum-free medium for $42 \mathrm{~h}$; PPF $\rightarrow 200 \mathrm{U} / \mathrm{ml}$ ulinastatin groups were defined as pretreatment with PPF $(10,20,30 \mu \mathrm{M})$ for $6 \mathrm{~h}$, followed by aspiration, one wash with $\mathrm{PBS}$, and $200 \mathrm{U} / \mathrm{ml}$ ulinastatin treatment for $42 \mathrm{~h}$.

Cell viability inhibition assay. The viability of PPF and ulinastatin against A549 cells was evaluated using the MTT assay. Twenty $\mu \mathrm{l} /$ well of $5 \mathrm{mg} / \mathrm{ml}$ MTT solution (Sigma-Aldrich; Merck KGaA) was added to each well and the cultures were further incubated for $4 \mathrm{~h}$. Optical density (OD) was measured at $490 \mathrm{~nm}$ on a multimode microplate reader (MDS; SpectraMax M5, San Jose, CA, USA). Viability inhibition rate was calculated as follows: Viability inhibition $(\%)=[1-(\mathrm{OD} 490 \mathrm{~nm}$ of treated cells-blank/OD490 nm of control cells-blank)] x100 (19). To determine whether the sequential treatments with ulinastatin and PPF had a synergistic effect, the combination index (CI) of each sequential treatment was analyzed according to the method of Chou and Talaly (20). CI values of $<1,1$ and $>1$ indicate synergistic, additive, and antagonistic effects, respectively. By using CompuSyn 1.0 software (CompuSyn, Inc., Paramus, NJ, USA), the CI value was easily computed.

Cell proliferation cycle detection. A cell proliferation cycle detection kit (KeyGEN Bio TECH Ltd., Nanjing, China) was used to detect the cell proliferation cycle. Pretreated cells were fixed in $70 \%$ ethanol at $4^{\circ} \mathrm{C}$ for $12 \mathrm{~h}$. Cells were aspirated, gently washed twice with ice-cold PBS, centrifuged at $2,000 \times \mathrm{g}$ for $5 \mathrm{~min}$ at $4^{\circ} \mathrm{C}$, aspirated once again, and resuspended in $1 \mathrm{ml} \mathrm{PBS}$ containing $50 \mu \mathrm{g} / \mathrm{ml}$ RNase A for $30 \mathrm{~min}$ at $37^{\circ} \mathrm{C}$. The cells were then incubated with propidium iodide (PI) for $30 \mathrm{~min}$ at $4^{\circ} \mathrm{C}$ in the dark. The percentage of cells with different DNA contents relating to different phases of the cell cycle was measured by fluorescence-activated cell sorting (FACS) analysis.

Trans-well assay for migration. Pretreated A549 cells (100 $\mu \mathrm{l} /$ chamber at a density of $10 \times 10^{6}$ cells $/ \mathrm{ml}$ ) in serum-free medium were placed in the upper chamber of the trans-well inserts with free Matrigel matrix basement membrane. To attract cells, medium containing $10 \%$ FBS was placed in the bottom of the chamber. Cells in the upper membranes were wiped using a cotton swab after incubation for $24 \mathrm{~h}$. Migratory cells were treated with different treatments: Pre-fixation with methanol for $20 \mathrm{~min}$, aspiration, one wash with PBS, followed by $0.1 \%$ crystal violet staining for $10 \mathrm{~min}$, before three washes with PBS. Cells were photographed in 9 predetermined fields under an inverted microscope (IX71; Olympus, Center Valley, PA, USA) at magnification, x200 and images were scored using CompuSyn software.

Trans-well assay for invasion. Falcon cell culture inserts (pore size of $8 \mu \mathrm{m}$; Corning Inc., Corning, NY, USA) were pretreated with Matrigel matrix basement membrane (Corning Inc., Corning, NY, USA). Pretreated A549 cells (100 $\mu \mathrm{l} / \mathrm{chamber}$ at a density of $10 \times 10^{6}$ cells $/ \mathrm{ml}$ ) in serum-free medium were placed in the upper chamber of the trans-well inserts. To attract cells, medium containing 10\% FBS was placed in the bottom of the chamber. Cells in the upper membrane were wiped using a cotton swab after incubation for $24 \mathrm{~h}$. Invasive cells were treated with different treatments: Pre-fixation with methanol for 20 min, aspiration, one wash with PBS, followed by $0.1 \%$ crystal violet staining for $10 \mathrm{~min}$, before three washes with PBS. Cells were photographed in 9 predetermined fields under an inverted microscope (IX71; Olympus, Center Valley, PA, USA) at magnification, x200 and images were scored using CompuSyn software.

Annexin V-FITC/PI staining assay for apoptosis detection. The Annexin V-FITC apoptosis detection kit (Merck, Darmstadt, Germany) was used to detect apoptosis. Pretreated cells were harvested before centrifugation at $1,000 \mathrm{x} \mathrm{g}$ for $5 \mathrm{~min}$ at $18-24^{\circ} \mathrm{C}$. Then, cells were resuspended in $500 \mu 1 \mathrm{~lx}$ binding buffer, before incubation with Annexin $\mathrm{V}$ for $15 \mathrm{~min}$ at $18-24^{\circ} \mathrm{C}$ in the dark. The cells were gently resuspended in $500 \mu \mathrm{l} 1 \mathrm{X}$ binding 


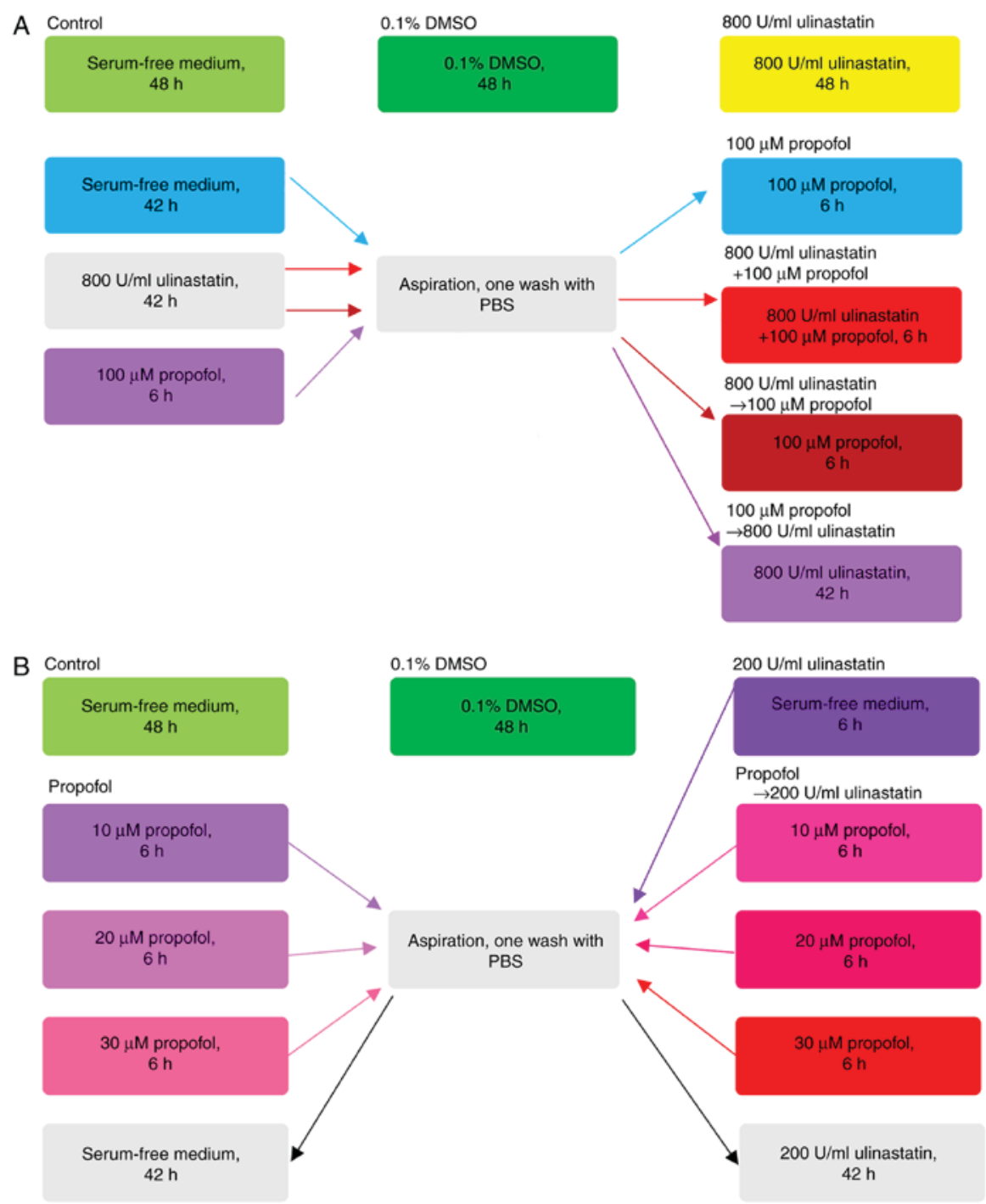

Figure 1. Different treatments schedules with PPF and ulinastatin for A549 cells. All compounds were dissolved in the serum-free medium. (A) To evaluate the antitumor effect of different treatment schedules relating to PPF and ulinastatin through high dose treatment, A549 cells were exposed to seven different treatments. $800 \mathrm{U} / \mathrm{ml}$ ulinastatin $+100 \mu \mathrm{M}$ PPF were dissolved in the same serum-free medium. (B) To verify the synergistic antitumor effect of PPF followed by ulinastatin treatments at low concentrations, A549 cells were exposed to nine different treatments.PBS phosphate buffer saline; PPF, propofol.

buffer. PI was added in the dark. The number of healthy viable cells, apoptotic, and necrotic cells were immediately measured by FACS analysis. The apoptosis rate was calculated as follows: The apoptosis rate $(\%)=($ number of apoptotic cells)/(number of total cells observed) x100 (21).

Western blot analysis. Pretreated cells were washed three times with ice-cold PBS and lysed with RIPA lysis buffer ( $1 \%$ Triton $\mathrm{X}-100,1 \%$ sodium deoxycholate, $0.1 \%$ sodium dodecyl sulfate, sodium salt, phosphatase inhibitor, and phenylmethanesulfonyl fluoride) (CW2333; CW Bio, Beijing, China). The cell extracts were collected, incubated for $30 \mathrm{~min}$ on ice, and centrifuged for $20 \mathrm{~min}$ at $12,000 \mathrm{x} \mathrm{g}$ at $4^{\circ} \mathrm{C}$. The supernatants were used as cell lysates. The cell lysates were subjected to SDS-polyacrylamide gel electrophoresis and transferred to polyvinylidene fluoride (PVDF) membranes after the bicinchoninic acid (BCA) method was used for protein quantification and equitable application of proteins to the gel. The membranes were blocked with $5 \%$ bovine serum albumin (BSA) in Tris-buffered saline (TBS) for $1 \mathrm{~h}$ at room temperature. After washing 3 times with TBS, the membranes were incubated in rabbit polyclonal antibodies (Cell Signaling Technology, Inc., Danvers, MA, USA) against ERK1/2, p-ERK1/2, and MMP-2 diluted with TBS containing $0.1 \%$ Tween-20 with 5\% BSA (TBST) before being gently agitated overnight at $4^{\circ} \mathrm{C}$. After washing 3 times with TBST, the membranes were incubated in fluorophore-conjugated secondary antibody (LI-COR Biosciences, Nebraska, USA) dilution buffer (TBS containing $0.1 \%$ Tween-20 with $5 \%$ skimmed dry milk) with gentle agitation for $1 \mathrm{~h}$ at room temperature. After washing 3 times with TBST, the Odyssey Infrared Imaging System (Licor, Lincoln, NE, USA) was used to detect proteins. The results were analyzed using ImageJ 1.42q software (Wayne Rasband National Institutes of Health, Bethesda, MD, USA).

Statistical analysis. Data were expressed as mean \pm standard deviation (SD) of three independent experiments. After determination of variance homogeneity of variance test, the Least-Significant-Difference and Dunnett' T3 were used to 
assess statistical significance, with $\mathrm{P}<0.05$ considered to indicate a statistically significant difference

\section{Results}

PPF followed by ulinastatin synergistically inhibited the viability of A549 cells. Fig. 2A shows that $100 \mu \mathrm{M}$ PPF inhibited the viability of A549 cells. However, $800 \mathrm{U} / \mathrm{ml}$ ulinastatin had no statistically significant in inhibiting the viability of A549 cells. $100 \mu \mathrm{M}$ PPF $\rightarrow 800 \mathrm{U} / \mathrm{ml}$ ulinastatin was the optimum sequence in inhibiting the viability of A549 cells. There was an antagonistic effect when A549 cells were treated with $800 \mathrm{U} / \mathrm{ml}$ ulinastatin $\rightarrow 100 \mu \mathrm{M}$ PPF, with the CI $>1$. Furthermore, there was an additive effect when A549 cells were treated with $800 \mathrm{U} / \mathrm{ml}$ ulinastatin $+100 \mu \mathrm{M}$ PPF, with the $\mathrm{CI}=1$. When A549 cells were treated with $100 \mu \mathrm{M}$ $\mathrm{PPF} \rightarrow 800 \mathrm{U} / \mathrm{ml}$ ulinastatin, the $\mathrm{CI}<1$, which indicates a synergistic effect.

From the results of the first experimental block, we found that the antitumor effect of the sequence PPF $\rightarrow$ ulinastatin at high concentration was the optimum sequence. To verify the synergistic antitumor effect of PPF $\rightarrow$ ulinastatin at low concentration, the results of the second experimental block were as follows. Fig. 2B demonstrates $200 \mathrm{U} / \mathrm{ml}$ ulinastatin and PPF groups $(10,20,30 \mu \mathrm{M})$ did not inhibit the viability of A549 cells. $10 \mu \mathrm{M}$ PPF $\rightarrow 200 \mathrm{U} / \mathrm{ml}$ ulinastatin did not significantly inhibit the viability of A549 cells. PPF (20 and $30 \mu \mathrm{M}) \rightarrow 200 \mathrm{U} / \mathrm{ml}$ ulinastatin synergistically inhibited the viability of A549 cells in a dose-dependent manner associated with PPF stimulation. There was a demonstrable antagonistic effect when A549 cells were treated with $10 \mu \mathrm{M}$ $\mathrm{PPF} \rightarrow 200 \mathrm{U} / \mathrm{ml}$ ulinastatin, where $\mathrm{CI}>1$, while there was a synergistic effect when A549 cells were treated with $20 \mu \mathrm{M}$ $\mathrm{PPF} \rightarrow 200 \mathrm{U} / \mathrm{ml}$ ulinastatin and $30 \mu \mathrm{M} \mathrm{PPF} \rightarrow 200 \mathrm{U} / \mathrm{ml}$ ulinastatin, where $\mathrm{CI}<1$.

PPF followed by ulinastatin synergistically increased the number of $S$ cells and reduced the number of $G 2 / M$ cells in a PPF dose-dependent manner. There were no statistically significant differences with respect to the number of $\mathrm{G} 0 / \mathrm{G} 1$ cells among groups (Fig. 3A). As shown in Fig. 3B, PPF groups $(10,20,30 \mu \mathrm{M})$ and $\mathrm{PPF} \rightarrow 200 \mathrm{U} / \mathrm{ml}$ ulinastatin groups significantly increased the number of S cells, but $0.1 \%$ DMSO and $200 \mathrm{U} / \mathrm{ml}$ ulinastatin did not significantly increase the number of S cells. PPF $(10,20$ and $30 \mu \mathrm{M}) \rightarrow 200 \mathrm{U} / \mathrm{ml}$ ulinastatin significantly increased the number of $\mathrm{S}$ cells respectively compared with PPF (10, 20 and $30 \mu \mathrm{M})$ and $200 \mathrm{U} / \mathrm{ml}$ ulinastatin in a PPF dose-dependent manner.

Fig. 3C shows the PPF groups $(20,30 \mu \mathrm{M})$ and PPF (10, $20,30 \mu \mathrm{M}) \rightarrow 200 \mathrm{U} / \mathrm{ml}$ ulinastatin groups significantly reduced the number of G2/M cells. However, $0.1 \%$ DMSO and $200 \mathrm{U} / \mathrm{ml}$ ulinastatin did not significantly reduce the number of $\mathrm{G} 2 / \mathrm{M}$ cells. PPF $\rightarrow 200 \mathrm{U} / \mathrm{ml}$ ulinastatin groups synergistically reduced the number of $\mathrm{G} 2 / \mathrm{M}$ cells compared with $200 \mathrm{U} / \mathrm{ml}$ ulinastatin.

$P P F \rightarrow$ ulinastatin treatments did not synergistically inhibit the migration and invasion of A549 cells. A549 cells were harvested and assayed for migration (Fig. 4A). $800 \mathrm{U} / \mathrm{ml}$ ulinastatin $\rightarrow 100 \mu \mathrm{M}$ PPF significantly reduced the migration of A549 cells compared with $100 \mu \mathrm{M}$ PPF, $800 \mathrm{U} / \mathrm{ml}$ ulinastatin $+100 \mu \mathrm{M} \mathrm{PPF}$, and $100 \mu \mathrm{M} \mathrm{PPF} \rightarrow 800 \mathrm{U} / \mathrm{ml}$ ulinastatin. There was no statistically significant difference in the inhibition of migration of A549 cells treated with $800 \mathrm{U} / \mathrm{ml}$ ulinastatin+ $100 \mu \mathrm{M}$ PPF, $800 \mathrm{U} / \mathrm{ml}$ ulinastatin $\rightarrow 100 \mu \mathrm{M}$ PPF, and $100 \mu \mathrm{M}$ $\mathrm{PPF} \rightarrow 800 \mathrm{U} / \mathrm{ml}$ ulinastatin, compared with $800 \mathrm{U} / \mathrm{ml}$ ulinastatin.

A549 cells were harvested and assayed for invasion (Fig.4B). The group of $100 \mu \mathrm{M}$ PPF treated A549 cells (56 \pm 5.0$)$ was better than control (70.1 \pm 4.4$) .800 \mathrm{U} / \mathrm{ml}$ ulinastatin $\rightarrow 100 \mu \mathrm{M}$ PPF significantly reduced the invasion of A549 cells compared with $100 \mu \mathrm{M}$ PPF, $800 \mathrm{U} / \mathrm{ml}$ ulinastatin $+100 \mu \mathrm{M}$ PPF, and $100 \mu \mathrm{M} \mathrm{PPF} \rightarrow 800 \mathrm{U} / \mathrm{ml}$ ulinastatin. $100 \mu \mathrm{M} \mathrm{PPF} \rightarrow 800 \mathrm{U} / \mathrm{ml}$ ulinastatin and $800 \mathrm{U} / \mathrm{ml}$ ulinastatin $+100 \mu \mathrm{M}$ PPF did not significantly reduce the invasion of A549 cells compared with $100 \mu \mathrm{M}$ PPF and $800 \mathrm{U} / \mathrm{ml}$ ulinastatin.

PPF followed by ulinastatin synergistically stimulated late apoptosis or necrosis in A549 cells. As shown in Fig. 5, compared with control, 0.1\% DMSO did not significantly stimulate late apoptosis or necrosis in A549 cells. However, $800 \mathrm{U} / \mathrm{ml}$ ulinastatin, $100 \mu \mathrm{M}$ PPF, $800 \mathrm{U} / \mathrm{ml}$ ulinastatin $+100 \mu \mathrm{M}$ PPF, $800 \mathrm{U} / \mathrm{ml}$ ulinastatin $\rightarrow 100 \mu \mathrm{M}$ $\mathrm{PPF}$, and $100 \mu \mathrm{M} \mathrm{PPF} \rightarrow 800 \mathrm{U} / \mathrm{ml}$ ulinastatin stimulated apoptosis or necrosis in A549 cells. $800 \mathrm{U} / \mathrm{ml}$ ulinastatin $+100 \mu \mathrm{M}$ $\mathrm{PPF}$ and $100 \mu \mathrm{M} \mathrm{PPF} \rightarrow 800 \mathrm{U} / \mathrm{ml}$ ulinastatin stimulated late apoptosis or necrosis in A549 cells to a significantly greater extent than $800 \mathrm{U} / \mathrm{ml}$ ulinastatin, $100 \mu \mathrm{M}$ PPF, and $800 \mathrm{U} / \mathrm{ml}$ ulinastatin $\rightarrow 100 \mu \mathrm{M}$ PPF treatments. There were no statistically significant differences on the viability of treated groups with respect to early apoptotic cells.

Effects of PPF $\rightarrow$ ulinastatin at low concentrations on the expression of $p-E R K 1 / 2$ and MMP-2. The expression of total ERK1/2 was not significantly different among all groups. However, the expression of p-ERK1/2 was different from total ERK1/2 (Fig. 6A). $200 \mathrm{U} / \mathrm{ml}$ ulinastatin, $10 \mu \mathrm{M} \mathrm{PPF}$, and $20 \mu \mathrm{M}$ PPF did not downregulate the expression of p-ERK1/2 in A549 cells. However, $30 \mu \mathrm{M}$ PPF and PPF $(10,20,30 \mu \mathrm{M}) \rightarrow 200 \mathrm{U} / \mathrm{ml}$ ulinastatin significantly reduced the expression of $\mathrm{p}-\mathrm{ERK} 1 / 2$. The expression of p-ERK1/2 was synergistically downregulated by $\operatorname{PPF}(10,20,30 \mu \mathrm{M}) \rightarrow 200 \mathrm{U} / \mathrm{ml}$ ulinastatin.

$0.1 \%$ DMSO, $200 \mathrm{U} / \mathrm{ml}$ ulinastatin, and PPF groups (10, 20, $30 \mu \mathrm{M}$ ) did not downregulate the expression of MMP-2 (Fig. 6B). Compared with $200 \mathrm{U} / \mathrm{ml}$ ulinastatin alone, the expression of MMP-2 was significantly downregulated after cells were treated with PPF $(10,20,30 \mu \mathrm{M}) \rightarrow 200 \mathrm{U} / \mathrm{ml}$ ulinastatin. $10 \mu \mathrm{M} \mathrm{PPF} \rightarrow 200 \mathrm{U} / \mathrm{ml}$ ulinastatin downregulated the expression of MMP-2 compared with $10 \mu \mathrm{M}$ PPF. However, there was no statistically significant difference when cells were treated with $20 \mu \mathrm{M} \mathrm{PPF} \rightarrow 200 \mathrm{U} / \mathrm{ml}$ ulinastatin or $30 \mu \mathrm{M}$ $\mathrm{PPF} \rightarrow 200 \mathrm{U} / \mathrm{ml}$ ulinastatin, compared with $20 \mu \mathrm{M}$ PPF or $30 \mu \mathrm{M}$ PPF.

\section{Discussion}

Among all types of lung cancers, adenocarcinoma accounts for $\sim 40 \%$ of cancer and generally has a poor prognosis (1). The A549 cell line is the typical cell line in human lung adenocarcinoma and surgery is the primary treatment for lung cancer. 

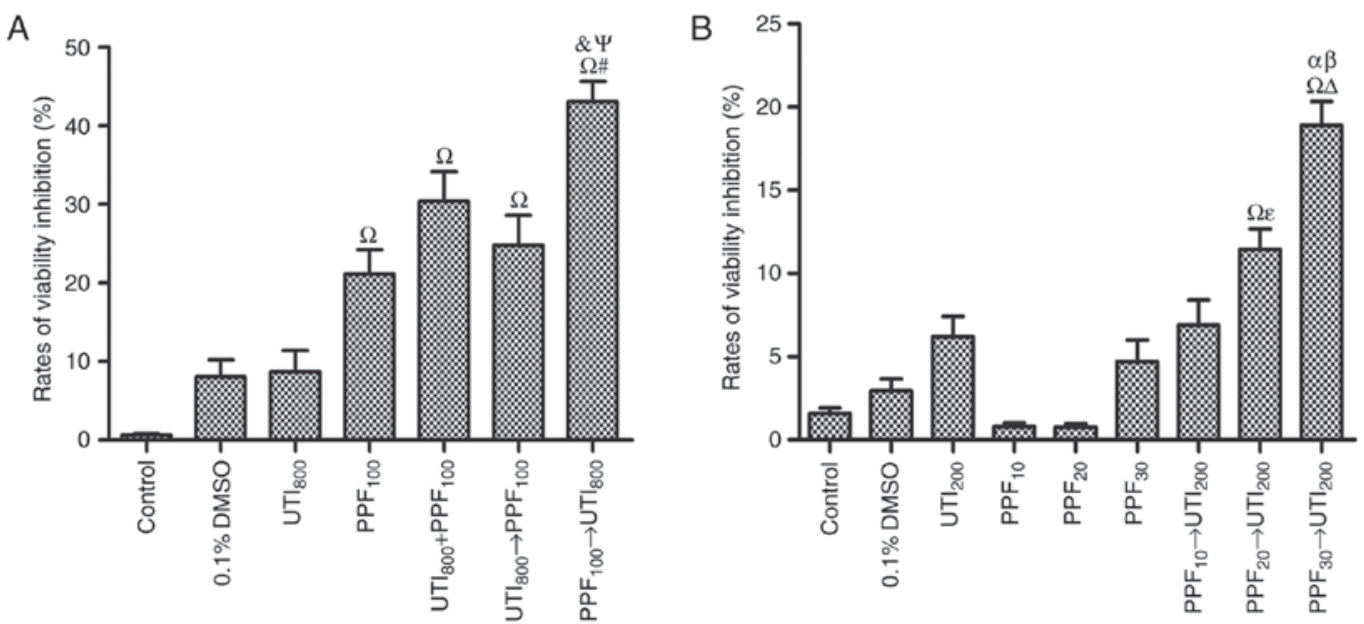

Figure 2. Viability assay of ulinastatin and PPF in A549 cells. A549 cells were inhibited using different groups and data were obtained from three independent experiments. Data were presented as mean \pm SD of three independent experiments, and analyzed by the Least-Significant-Difference. (A) Antitumor effects of different sequential administration with $800 \mathrm{U} / \mathrm{ml}$ ulinastatin $\left(\mathrm{UTI}_{800}\right)$ and $100 \mu \mathrm{M} \mathrm{PPF}\left(\mathrm{PPF}_{100}\right)$; (B) The synergistic effect of PPF $\rightarrow$ ulinastatin at clinical concentrations. ${ }^{\Omega} \mathrm{P}<0.05$ vs. Control; ${ }^{*} \mathrm{P}<0.05$ vs. $\mathrm{UTI}_{800} ;{ }^{\circ} \mathrm{P}<0.05$ vs. $200 \mathrm{U} / \mathrm{ml}$ ulinastatin $\left(\mathrm{UTI}_{200}\right)$; ${ }^{\&} \mathrm{P}<0.05$ vs. $\mathrm{PPF} \mathrm{F}_{100} ;{ }^{\Psi} \mathrm{P}<0.05$ vs. $800 \mathrm{U} / \mathrm{ml} \mathrm{ulina}-$ statin $\rightarrow 100 \mu \mathrm{M}$ PPF $\left(\mathrm{UTI}_{800} \rightarrow \mathrm{PPF}_{100}\right) ;{ }^{\alpha} \mathrm{P}<0.05$ vs. $30 \mu \mathrm{M}$ PPF $\left(\mathrm{PPF}_{30}\right) ;{ }^{\beta} \mathrm{P}<0.05$ vs. $10 \mu \mathrm{M} \mathrm{PPF} \rightarrow 200 \mathrm{U} / \mathrm{ml}$ ulinastatin $\left(\mathrm{PPF}_{10} \rightarrow \mathrm{UTI}_{200}\right) ;{ }^{\mathrm{e}} \mathrm{P}<0.05$ vs. $20 \mu \mathrm{M}$ $\mathrm{PPF}\left(\mathrm{PPF}_{20}\right)$. PPF, propofol.

A

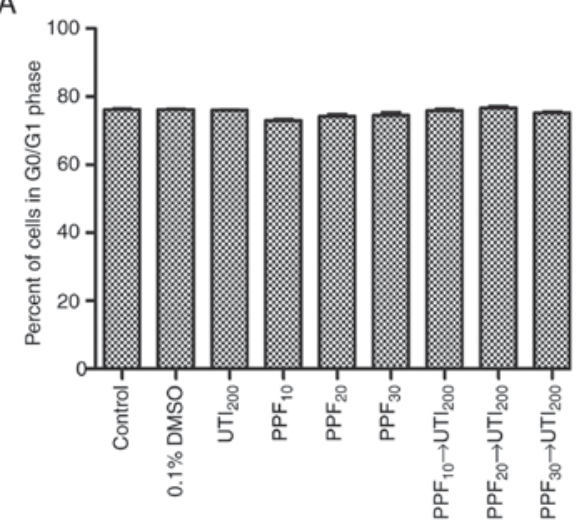

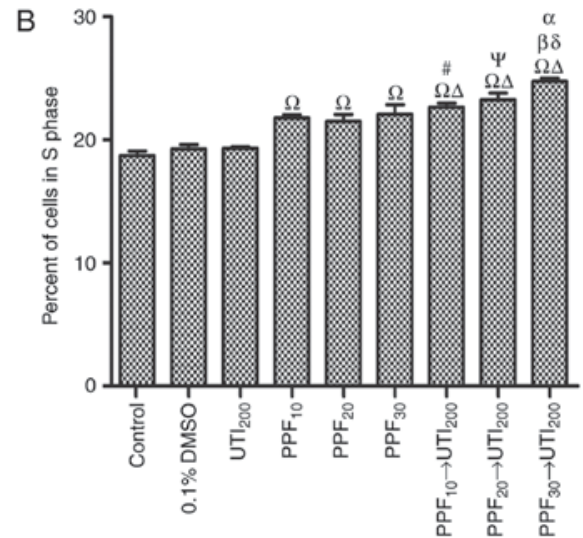

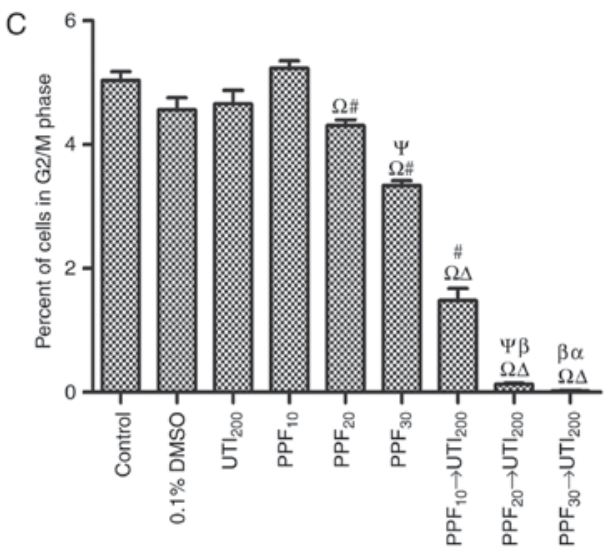

Figure 3. A549 cell proliferation cycle of PPF $\rightarrow$ ulinastatin at clinical concentrations. A549 cells were inhibited using different groups and data were obtained from three independent experiments. Data were presented as mean \pm SD of three independent experiments, and analyzed by the Least-Significant-Difference. (A) Percentage of A549 cells in G0/G1 phase; (B) Percentage of A549 cells in S phase; (C) Percentage of A549 cells in G2/M phase. ${ }^{\Omega} \mathrm{P}<0.05$ vs. Control; ${ }^{\#} \mathrm{P}<0.05$ vs. $10 \mu \mathrm{M}$ PPF $\left(\mathrm{PPF}_{10}\right) ;{ }^{\circ} \mathrm{P}<0.05$ vs. $200 \mathrm{U} / \mathrm{ml}$ ulinastatin $\left(\mathrm{UTI}_{200}\right) ;{ }^{\psi} \mathrm{P}<0.05$ vs. $20 \mu \mathrm{M} \mathrm{PPF}\left(\mathrm{PPF}_{20}\right) ;{ }^{\alpha} \mathrm{P}<0.05$ vs. $30 \mu \mathrm{M}$ PPF $\left(\mathrm{PPF}_{30}\right) ;{ }^{\beta} \mathrm{P}<0.05$ vs. $10 \mu \mathrm{M}$ $\mathrm{PPF} \rightarrow 200 \mathrm{U} / \mathrm{ml}$ ulinastatin $\left(\mathrm{PPF}_{10} \rightarrow \mathrm{UTI}_{200}\right)$; ${ }^{\circledR} \mathrm{P}<0.05$ vs. $20 \mu \mathrm{M} \mathrm{PPF} \rightarrow 200 \mathrm{U} / \mathrm{ml}$ ulinastatin $\left(\mathrm{PPF}_{20} \rightarrow \mathrm{UTI}_{200}\right)$. PPF, propofol.

The immunosuppressive effects of surgery are well known with respect to cancer progression (22). Surgery can also generate a microenvironment that is abundant in inflammatory cells and growth factors, including potent angiogenic, lymphangiogenic growth factors, cytokines, and proteases (23). Granov et al found that cancer patients were susceptible in developing acute lung lesions (ALL) and adult respiratory distress syndrome (ARDS) postoperatively (24). Use of ulinastatin and PPF may 

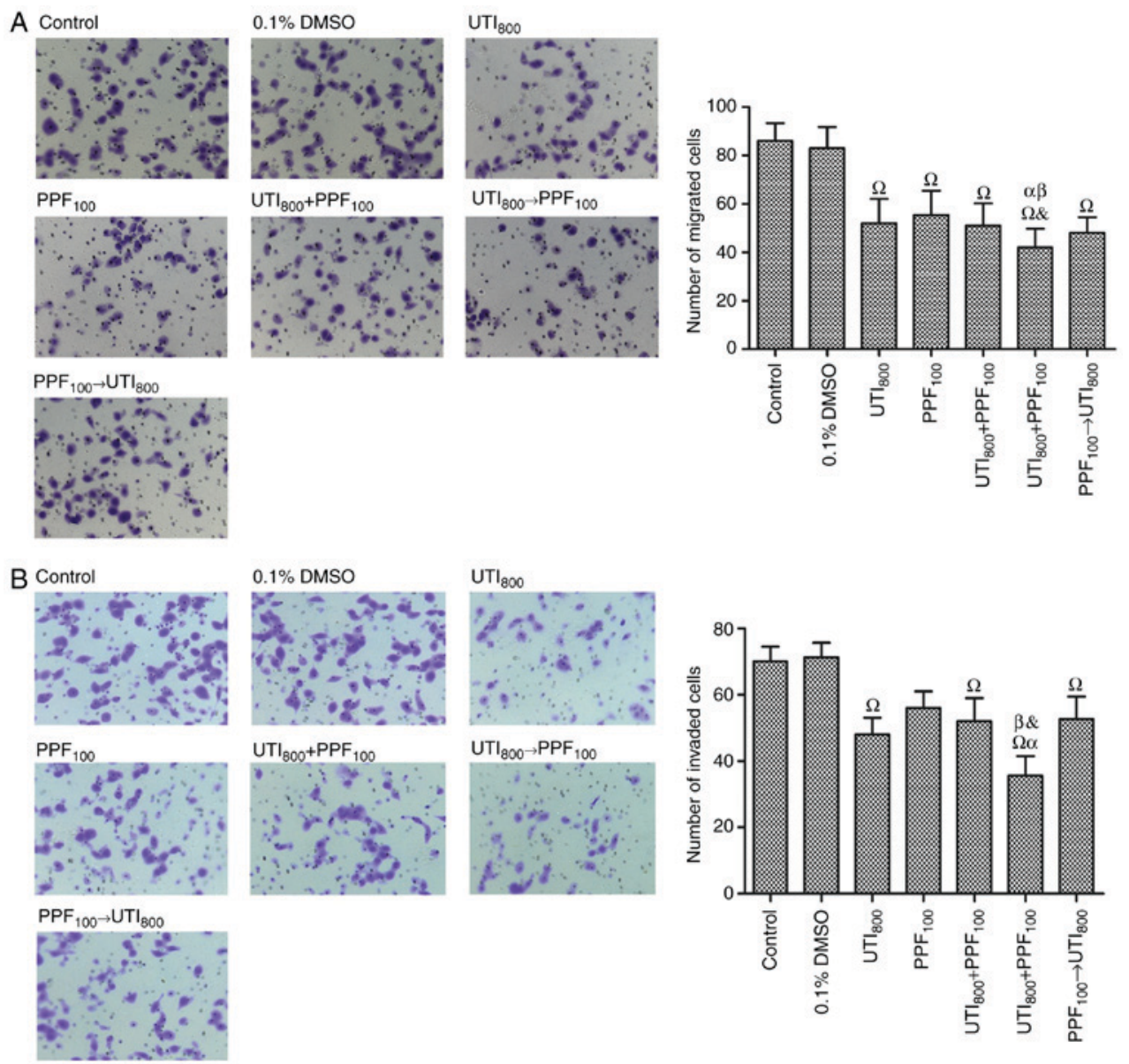

Figure 4. Effect of ulinastatin and PPF on invasion and migration of A549 cells. Cells that had migrated (A) and invaded (B) were photographed (magnification, x200), and photographed in 9 predetermined fields for each treatment. Data were calculated from three independent experiments. Data were presented as mean $\pm \mathrm{SD}$ of three independent experiments and analyzed by Dunnett' T3. ${ }^{\Omega} \mathrm{P}<0.05$ vs. Control; ${ }^{\circledR} \mathrm{P}<0.05 \mathrm{vs} .100 \mu \mathrm{M} \mathrm{PPF}\left(\mathrm{PPF}{ }_{100}\right) ;{ }^{a} \mathrm{P}<0.05 \mathrm{vs} .800 \mathrm{U} / \mathrm{ml}$ ulinastatin $+100 \mu \mathrm{M}$ PPF $\left(\mathrm{UTI}_{800}+\mathrm{PPF}_{100}\right) ;{ }^{\beta} \mathrm{P}<0.05$ vs. $100 \mu \mathrm{M} \mathrm{PPF} \rightarrow 800 \mathrm{U} / \mathrm{ml}$ ulinastatin $\left(\mathrm{PPF}_{100} \rightarrow \mathrm{UTI}_{800}\right)$. PPF, propofol.

benefit ARDS patients through different mechanisms (17). PPF exhibits protective effects including an antiinflammatory effect, enhancement of antitumor immunity, reduction of the concentration of cytokines (IL-1, TNF- $\alpha$ and IL-6) and natural killer cell function preservation (25-28). Ulinastatin also improves the immunosuppressive state during surgery for malignancy (29). In view of the clinical translation of our results, the optimum administration protocol (PPF $\rightarrow$ ulinastatin) may benefit ARDS patients and inhibit lung adenocarcinoma cells, which can improve the postoperative prognosis of lung adenocarcinoma patients. PPF $\rightarrow$ ulinastatin synergistic antitumor effects may be importantly related to the immune microenvironment. As ERK1/2 phosphorylation is an important step for cytokine secretion such as TNF- $\alpha$ (30) and IL-1 $\beta$ (31), PPF $\rightarrow$ ulinastatin may synergistically reduce cytokine secretion of TNF- $\alpha$ and IL-1 $\beta$ by inhibiting ERK1/2 phosphorylation in A549 cells.

With respect to clinical application, $100 \mu \mathrm{M}$ PPF and $800 \mathrm{U} / \mathrm{ml}$ ulinastatin was more potent but PPF $(6.2-33.7 \mu \mathrm{M})$ administered through Target Controlled Infusion (TCI) is widely used in clinical applications (e.g., the maintenance of general anesthesia), and $200 \mathrm{U} / \mathrm{ml}$ ulinastatin is introduced in a pharmacy. To verify the synergistic effect of PPF $\rightarrow$ ulinastatin at a clinical concentration, we tested several concentration gradients of PPF using TCI $(10,20,30 \mu \mathrm{M})$ and a clinical concentration of ulinastatin $(200 \mathrm{U} / \mathrm{ml})$. We demonstrated that $\mathrm{PPF} \rightarrow$ ulinastatin treatments effectively inhibited the viability of A549 cells and stimulated late apoptosis or necrosis cells. However, PPF $\rightarrow$ ulinastatin treatments did not synergistically inhibit the migration and invasion of A549 cells. From the results, we found that the molecular mechanisms regulating the viability and late apoptosis or necrosis of A549 cells might share common properties from which regulating the migration and invasion of A549 cells was different.

In our investigation, the MTT assay clearly indicated that PPF $\rightarrow$ ulinastatin treatments had a synergistic effect at high and low concentrations in inhibiting A549 cell viability. $\mathrm{PPF} \rightarrow$ ulinastatin synergistically inhibited A549 cell viability, which could be attributed to the different timing events in the cell cycle: PPF $\rightarrow$ ulinastatin treatments synergistically increased the number of $\mathrm{S}$ cells and synergistically reduced the number of $\mathrm{G} 2 / \mathrm{M}$ cells in a PPF dose-dependent manner. The G2/M DNA damage checkpoint serves to prevent the cell from entering M-phase, which can result in genomic damage. DNA damage can activate the DNA-PK/ATM/ATR kinases, which result in two parallel cascades that ultimately serve to inactivate the cyclin B-cdc2 kinase. The first cascade rapidly inhibits progression into mitosis: The Chk kinases phosphorylate and inactivate cdc25, which prevents activation of cdc2 $(32,33)$. Phosphorylated ERK1/2 (p-ERK1/2) activates 
A
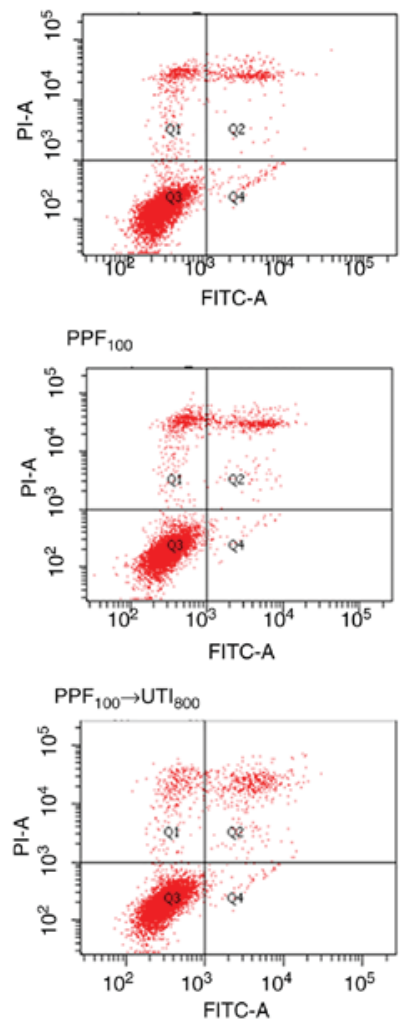

$0.1 \%$ DMSO

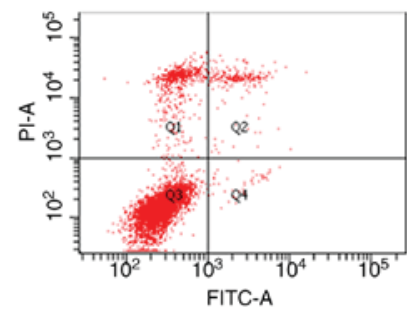

$\mathrm{UTI}_{800}+\mathrm{PPF}_{100}$
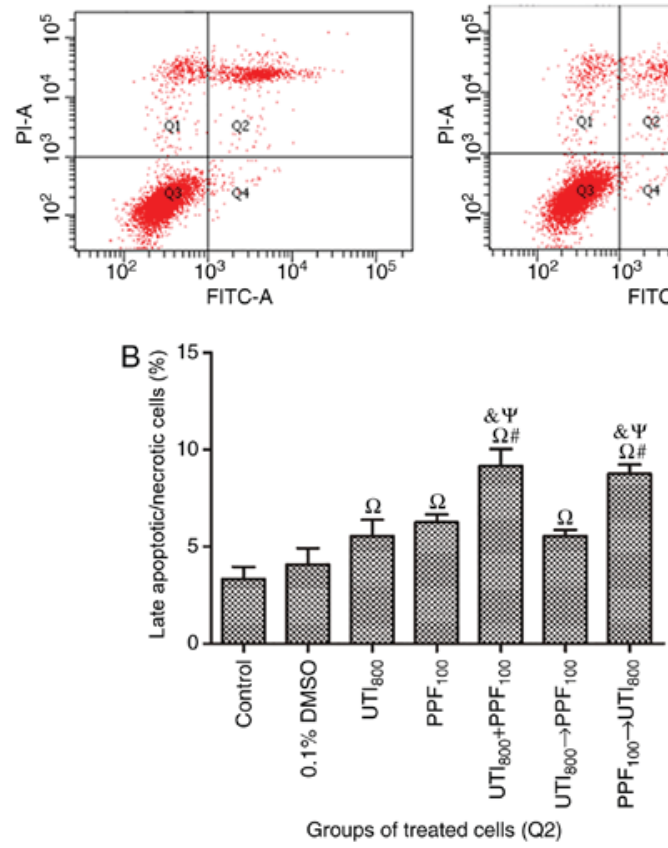

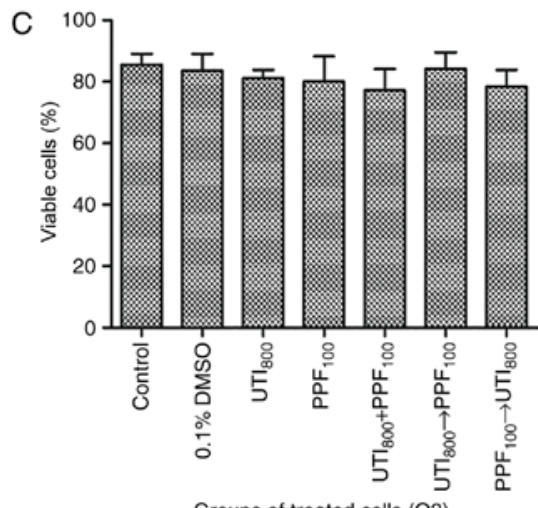

Figure 5. Effect of ulinastatin and PPF on apoptosis of A549 cells. Annexin V-FITC/PI staining assay. After different treatments, cells were labeled and sorted using flow cytometry. (A) Late apoptotic or necrotic cells in Q2 (B) are depicted in the upper right-hand quadrant of the dot plot; viable cells in Q3 (C) are depicted in the lower left-hand quadrant of the dot plot. Data were calculated from three independent experiments. Data were presented as mean \pm SD of three independent experiments and analyzed by the Least-Significant-Difference. For late apoptotic or necrotic cells, ${ }^{\Omega} \mathrm{P}<0.05$ vs. Control; ${ }^{\#} \mathrm{P}<0.05$ vs. $800 \mathrm{U} / \mathrm{ml}$ ulinastatin $\left(\mathrm{UTI}_{800}\right) ;{ }^{\&} \mathrm{P}<0.05$ vs. $100 \mu \mathrm{M}$ PPF $\left(\mathrm{PPF}_{100}\right) ;{ }^{\Psi} \mathrm{P}<0.05$ vs. $800 \mathrm{U} / \mathrm{ml}$ ulinastatin $\rightarrow 100 \mu \mathrm{M}$ PPF $\left(\mathrm{UTI}_{800} \rightarrow \mathrm{PPF}_{100}\right)$. For early apoptotic and viable cells vs. Control, all P-values of treated groups $>0.05$. PI, propidium iodide; PPF, propofol.

cdc25, which promotes the cell from entering M-phase (34). ERK1/2 is activated through phosphorylation, which plays an important role in the regulation of fundamental cellular processes including proliferation, survival, differentiation, migration (35-37), and apoptosis (38). It has been reported that $100 \mu \mathrm{M}$ (7) PPF can downregulate the expression of p-ERK1/2 in A549 cells. Liposoluble PPF is liable to pass through the A549 cytomembrane into the cytoplasm and nucleus, which may inactivate ERK1/2 and/or promote DNA damage in A549 cells. This DNA damage may improve the dosing of soluble ulinastatin in the cytoplasm and nucleus of A549 cells, which synergistically inactivate $\mathrm{p}-\mathrm{ERK} 1 / 2, \mathrm{cdc} 2$, and/or cdc25. The DNA-PK/ATM/ATR kinases from DNA damage are inactivated by ulinastatin, which counteracts the DNA damage in A549 cells caused by PPF. We believe these were the reasons why the treatment with $\mathrm{PPF} \rightarrow$ ulinastatin was more effective than both ulinastatin $\rightarrow$ PPF and the simultaneous combination.

The suppression of ERK1/2 and hypoxia pathways resulted in the suppression of MMP-2, MMP-9, and MMP-7 

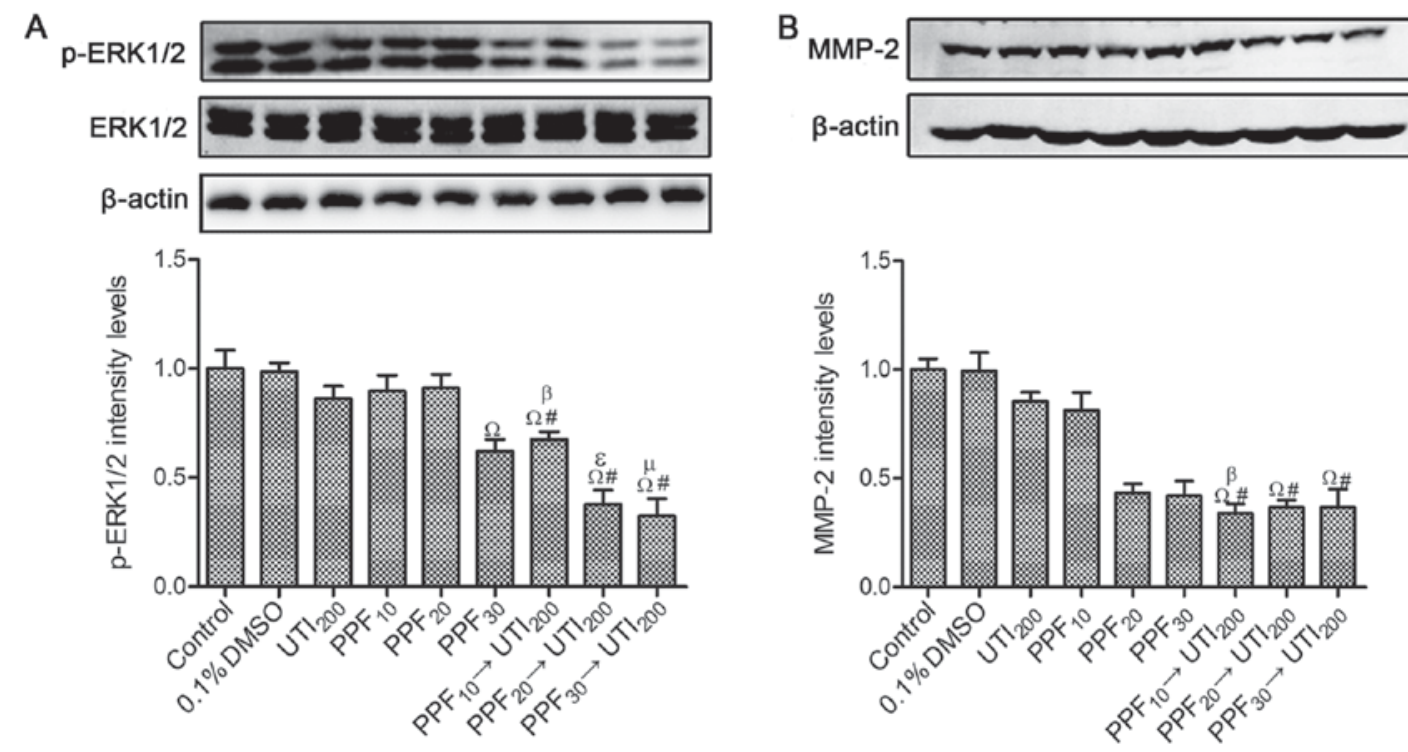

Figure 6. Effects of treatment with ulinastatin, PPF, and PPF $\rightarrow$ ulinastatin on the protein expression of p-ERK1/2 (A) and MMP-2 (B) in A549 cells. Data were calculated from three independent experiments. Data were presented as mean $\pm \mathrm{SD}$ of three independent experiments, and analyzed by the Least-Significant-Difference. ${ }^{\Omega} \mathrm{P}<0.05$ vs. Control; ${ }^{*} \mathrm{P}<0.05$ vs. $200 \mathrm{U} / \mathrm{ml}$ ulinastatin $\left(\mathrm{UTI}_{200}\right){ }^{\beta} \mathrm{P}<0.05$ vs. $10 \mu \mathrm{M}$ PPF $\left(\mathrm{PPF}_{10}\right) ;{ }^{\varepsilon} \mathrm{P}<0.05$ vs. $20 \mu \mathrm{M}$ PPF $\left(\mathrm{PPF}_{20}\right)$; ${ }^{\mu} \mathrm{P}<0.05$ vs. $30 \mu \mathrm{M}$ PPF $\left(\mathrm{PPF}_{30}\right)$. p-ERK, extracellular signal-regulated kinase phosphorylation; MMP, matrix metalloproteinases; PPF, propofol.

expression in A549 cell metastasis (39). Metalloproteinases, particularly MMP-2, play an important role in the regulation of fundamental cancer cellular processes including cell growth, invasion, inflammation and angiogenesis (40). PPF suppresses the invasion and migration of A549 human lung adenocarcinoma epithelial cells by downregulating the expression of MMP-2 and p38 MAPK signaling (6). It has been reported that a urinary trypsin inhibitor-like inhibitor can be isolated from human lung cancer tissue (41). In our study, we suspected that ulinastatin did not statistically inhibit the viability of A549 cells because of the presence of the inhibitor from human lung cancer tissues or the low concentration of ulinastatin. Two hundred $\mathrm{U} / \mathrm{ml}$ of ulinastatin alone did not effectively inhibit the expression of MMP-2 due to the inhibitor or the low concentration of ulinastatin. PPF alone did not effectively inhibit the expression of MMP-2 due to the low concentration of PPF. However, the expression of MMP-2 after PPF $\rightarrow$ ulinastatin treatment was synergistically downregulated as pretreated A549 cells with PPF could regulate expression of the inhibitor.

In our study, we have partly elucidated the underlying mechanisms of the synergistic antitumor effect of $\mathrm{PPF} \rightarrow$ ulinastatin at clinical concentrations, and detected p-ERK1/2 and MMP-2. DNA-PK/ATM/ATR, Cyclin B-cdc2, and Chk kinases in A549 cells will be detected to verify the mechanism of G2/M DNA damage and how this relates to synergistic suppression of the human lung adenocarcinoma epithelial A549 cell line with PPF treatment followed by ulinastatin.

In summary, we conclude that PPF $(20,30 \mu \mathrm{M})$ followed by $200 \mathrm{U} / \mathrm{ml}$ ulinastatin treatments synergistically stimulated a significant proportion of A549 cells in S phase, synergistically reduced the percent of A549 cells in G2/M phase, and synergistically suppressed viability, which could possibly be related to regulating the expression of p-ERK1/2 and MMP-2 in A549 cells.

\section{Acknowledgements}

Not applicable.

\section{Funding}

The present study was supported in part by the Scheme of the Guandong Province Sciences Research (grant no. 2012A030400014).

\section{Availability of data and materials}

All data generated or analyzed during this study are included in this published article.

\section{Authors' contributions}

PL and PG assisted in the design of the study, conducedt the study, analyze the data and wrote the manuscript. CL assisted in the analysis of the statistics, interpreted the data and graphic illustrations and drafted the manuscript. MH, XZ, CL, JT, WW and WL collaborated in the design of the study and assisted in writing the manuscript. All authors read and approved the final manuscript.

\section{Ethics approval and consent to participate}

Not applicable.

\section{Patient consent for publication}

Not applicable.

\section{Competing interests}

The authors declare that they have no competing interests. 


\section{References}

1. Yan KH, Lee LM, Yan SH, Huang HC, Li CC, Lin HT and Chen PS: Tomatidine inhibits invasion of human lung adenocarcinoma cell A549 by reducing matrix metalloproteinases expression. Chem Biol Interact 203: 580-587, 2013.

2. Tyzzer EE: Factors in the production and growth of tumor metastases. J Med Res 28: 309-332.1, 1913.

3. Demicheli R, Retsky MW, Hrushesky WJ, Baum M and Gukas ID: The effects of surgery on tumor growth: a century of investigations. Ann Oncol 19: 1821-1828, 2008.

4. Allen-Mersh TG, McCullough TK, Patel H, Wharton RQ, Glover C and Jonas SK: Role of circulating tumour cells in predicting recurrence after excision of primary colorectal carcinoma. Br J Surg 94: 96-105, 2007.

5. Cassinello F, Prieto I, del Olmo M, Rivas S and Strichartz GR: Cancer surgery: How may anesthesia influence outcome? J Clin Anesth 27: 262-272, 2015.

6. Wu KC, Yang ST, Hsia TC, Yang JS, Chiou SM, Lu CC, Wu RS and Chung JG: Suppression of cell invasion and migration by propofol are involved in down-regulating matrix metalloproteinase-2 and p38 MAPK signaling in A549 human lung adenocarcinoma epithelial cells. Anticancer Res 32: 4833-4842, 2012.

7. Song J, Shen Y, Zhang J and Lian Q: Mini profile of potential anticancer properties of propofol. PLoS One 9: e114440, 2014.

8. Kobayashi H, Shinohara H, Takeuchi K, Itoh M, Fujie M, Saitoh M and Terao T: Inhibition of the soluble and the tumor cell receptor-bound plasmin by urinary trypsin inhibitor and subsequent effects on tumor cell invasion and metastasis. Cancer Res 54: 844-849, 1994.

9. Kobayashi H, Gotoh J, Fujie M and Terao T: Characterization of the cellular binding site for the urinary trypsin inhibitor. J Biol Chem 269: 20642-20647, 1994.

10. Kobayashi H, Gotoh J, Kanayama N, Hirashima Y, Terao T and Sugino D: Inhibition of tumor cell invasion through matrigel by a peptide derived from the domain II region in urinary trypsin inhibition. Cancer Res 55: 1847-1852, 1995

11. Kobayashi H, Shinohara H, Fujie M, Gotoh J, Itoh M, Takeuchi K and Terao T: Inhibition of metastasis of Lewis lung carcinoma by urinary trypsin inhibitor in experimental and spontaneous metastasis models. Int J Cancer 63: 455-462, 1995.

12. Kobayashi H: Mechanism of tumor cell-induced extracellular matrix degradation-inhibition of cell-surface proteolytic activity might have a therapeutic effect on tumor cell invasion and metastasis. Nihon Sanka Fujinka Gakkai zasshi 48: 623-632, 1996 (In Japanese).

13. Yoshioka I, Tsuchiya Y, Aozuka Y, Onishi Y, Sakurai H, Koizumi K, Tsukada K and Saiki I: Urinary trypsin inhibitor suppresses surgical stress-facilitated lung metastasis of murine colon 26-L5 carcinoma cells. Anticancer Res 25: 815-820, 2005.

14. Kobayashi H, Shinohara H, Gotoh J, Fujie M, Fujishiro S and Terao T: Anti-metastatic therapy by urinary trypsin inhibitor in combination with an anti-cancer agent. Br J Cancer 72: 1131-1137, 1995.

15. Song B, Bian Q, Shao CH, Li G, Liu AA, Jing W, Liu R, Zhang YJ, Zhou YQ, Hu XG and Jin G: Ulinastatin reduces the resistance of liver cancer cells to epirubicin by inhibiting autophagy. PLoS One 10: e0120694, 2015.

16. Gao F, Sun Z, Sun X, Zhang Y, Wang H, Zhong B, Luo J and Zhao X: Ulinastatin exerts synergistic effects with taxotere and inhibits invasion and metastasis of breast cancer by blocking angiogenesis and the epithelial-mesenchymal transition. Cancer Biother Radiopharm 28: 218-225, 2013.

17. Yuan SM: Postperfusion lung syndrome: Respiratory mechanics, respiratory indices and biomarkers. Ann Thorac Med 10: 151-157, 2015.

18. Lu HL and Qian YN: Protective effects of propofol combined with ulinastatin on acute lung injury induced by endotoxin in rats. Zhongguo Ying Yong Sheng Li Xue Za Zhi 29: 56-57, 62, 2013 (In Chinese).

19. Vinodhkumar R, Song YS, Ravikumar V, Ramakrishnan G and Devaki T: Depsipeptide a histone deacetlyase inhibitor down regulates levels of matrix metalloproteinases 2 and 9 mRNA and protein expressions in lung cancer cells (A549). Chem Biol Interact 165: 220-229, 2007.

20. Ashton JC: Drug combination studies and their synergy quantification using the Chou-Talalay method-letter. Cancer Res 75 : 2400,2015
21. Yousef BA, Hassan HM, Guerram M, Hamdi AM, Wang B, Zhang LY and Jiang ZZ: Pristimerin inhibits proliferation, migration and invasion, and induces apoptosis in HCT-116 colorectal cancer cells. Biomed Pharmacother 79: 112-119, 2016.

22. Page GG: Surgery-induced immunosuppression and postoperative pain management. AACN Clin Issues 16: 302-309; quiz 416-418, 2005.

23. Coussens LM and Werb Z: Inflammation and cancer. Nature 420 860-867, 2002.

24. Granov AM, Rozenberg OA, Tsybul'kin EK, Erokhin VV, Khubulava GG, Likhvantsev VV, Osovskikh VV, Bautin AE, Gavrilin SV, Kazennov VV, et al: Critical state medicine. Surfactant therapy of adult respiratory distress syndrome (results of multicenter studies). Vestn Ross Akad Med Nauk: 34-38, 2001 (In Russian).

25. Ke JJ,Zhan J, Feng XB, Wu Y, Rao Y and Wang YL: A comparison of the effect of total intravenous anaesthesia with propofol and remifentanil and inhalational anaesthesia with isoflurane on the release of pro- and anti-inflammatory cytokines in patients undergoing open cholecystectomy. Anaesth Intensive Care 36: 74-78, 2008.

26. Kushida A, Inada T and Shingu K: Enhancement of antitumor immunity after propofol treatment in mice. Immunopharmacol Immunotoxicol 29: 477-486, 2007.

27. Zhou W,Fontenot HJ, Wang SN and Kennedy RH:Propofol-induced alterations in myocardial beta-adrenoceptor binding and responsiveness. Anesth Analg 89: 604-608, 1999.

28. González-Correa JA, Cruz-Andreotti E, Arrebola MM, López-Villodres JA, Jódar M and De La Cruz JP: Effects of propofol on the leukocyte nitric oxide pathway: In vitro and ex vivo studies in surgical patients. Naunyn Schmiedebergs Arch Pharmacol 376: 331-339, 2008.

29. Hosokawa T, Hori Y, Nakagawa H, Nakagawa M, Hashimoto T and Miyazaki M: Effect of urinastatin on immunity during anesthesia and surgery for malignant disease. Masui 38: 1341-1348, 1989.

30. Guzmán-Mejía F, López-Rubalcava C and González-Espinosa C: Stimulation of $\mathrm{nAchR} \alpha 7$ receptor inhibits TNF synthesis and secretion in response to LPS treatment of mast cells by targeting ERK1/2 and TACE activation. J Neuroimmune Pharmacol 13: 39-52, 2018.

31. Mezzasoma L, Antognelli C and Talesa VN: A novel role for brain natriuretic peptide: Inhibition of IL- $1 \beta$ secretion via downregulation of NF-kB/Erk 1/2 and NALP3/ASC/caspase-1 activation in human THP-1 monocyte. Mediators Inflamm 2017: 5858315, 2017.

32. Al-Ejeh F, Kumar R, Wiegmans A, Lakhani SR, Brown MP and Khanna KK: Harnessing the complexity of DNA-damage response pathways to improve cancer treatment outcomes. Oncogene 29: 6085-6098, 2010

33. Okumura E, Fukuhara T, Yoshida H, Hanada Si S, Kozutsumi R, Mori M, Tachibana K and Kishimoto T: Akt inhibits Mytl in the signalling pathway that leads to meiotic G2/M-phase transition. Nat Cell Biol 4: 111-116, 2002

34. Yan Y, Black CP and Cowan KH: Irradiation-induced G2/M checkpoint response requires ERK1/2 activation. Oncogene 26: 4689-4698, 2007.

35. Cristea $\mathrm{S}$ and Sage J: Is the canonical RAF/MEK/ERK signaling pathway a therapeutic target in SCLC? J Thorac Oncol 11: 1233-1241, 2016

36. Frémin C, Saba-El-Leil MK, Lévesque K, Ang SL and Meloche S: Functional redundancy of ERK1 and ERK2 MAP kinases during development. Cell Rep 12: 913-921, 2015.

37. Fey D, Matallanas D, Rauch J, Rukhlenko OS and Kholodenko BN: The complexities and versatility of the RAS-to-ERK signalling system in normal and cancer cells. Semin Cell Dev Biol 58: 96-107, 2016

38. Persaud SD, Park SW, Ishigami-Yuasa M, Koyano-Nakagawa N, Kagechika $\mathrm{H}$ and Wei LN: All trans-retinoic acid analogs promote cancer cell apoptosis through non-genomic Crabp1 mediating ERK1/2 phosphorylation. Sci Rep 6: 22396, 2016.

39. Lee SH, Jaganath IB, Manikam R and Sekaran SD: Inhibition of Raf-MEK-ERK and hypoxia pathways by Phyllanthus prevents metastasis in human lung (A549) cancer cell line. BMC Complement Altern Med 13: 271, 2013.

40. Kessenbrock K, Plaks V and Werb Z: Matrix metalloproteinases: Regulators of the tumor microenvironment. Cell 141: 52-67, 2010.

41. Okumichi T, Nishiki M, Takasugi S, Toki $\mathrm{N}$ and Ezaki $\mathrm{H}$ Isolation of urinary trypsin inhibitor-like inhibitor from human lung cancer tissue. Cancer Res 44: 2011-2015, 1984.

This work is licensed under a Creative Commons Attribution-NonCommercial-NoDerivatives 4.0 International (CC BY-NC-ND 4.0) License. 